\title{
Correction to: Morpho-physiological and qualitative variation of domesticated einkorn (Triticum monococcum $\mathbf{L}$. ssp. monococcum)
}

\author{
Andrea Volante $\cdot$ Volkan Arif Yilmaz $\cdot$ Alyssa Hidalgo $\cdot$ Andrea Brandolini
}

Published online: 9 April 2020

(C) Springer Nature B.V. 2020

\section{Correction to:}

\section{Genet Resour Crop Evol}

https://doi.org/10.1007/s10722-020-00923-6

The original version of this article was revised: In the original publication of the article, the word "symbol" was mistakenly added to the article title.

The original article can be found online at https:// doi.org/10.1007/s10722-020-00923-6.
The correct version of the article title is provided in this Correction: Morpho-physiological and qualitative variation of domesticated einkorn (Triticum monococcum L. ssp. monococcum).

Publisher's Note Springer Nature remains neutral with regard to jurisdictional claims in published maps and institutional affiliations.
A. Volante

Consiglio per la ricerca in agricoltura e l'analisi

dell'economia agraria - Centro di Ricerca Cerealicoltura e Colture Industriali (CREA-CI), Strada Provinciale 11 per Torino km 2.5, 13100 Vercelli, Italy

e-mail: andrea.volante@crea.gov.it

\section{A. Yilmaz}

Food Engineering Department, Ondokuz May1s University, Kurupelit, 55139 Samsun, Turkey

e-mail: volkan.yilmaz@omu.edu.tr

\author{
A. Hidalgo \\ Department of Food, Environmental and Nutritional \\ Sciences (DeFENS), Università degli Studi di Milano, Via \\ Celoria 2, 20133 Milan, Italy \\ e-mail: alyssa.hidalgovidal@unimi.it
}

